\title{
Response to "Letter to the Editor regarding the report entitled Urinary sodium/potassium ratio as a screening tool for hyperaldosteronism in men with hypertension"
}

\author{
Hiroyoshi Segawa ${ }^{1,2} \cdot$ Akane Higashi $^{1} \cdot$ Kengo Yoshii $^{3} \cdot$ Toshiyuki Iwahori $^{4} \cdot$ Hirotsugu Ueshima $^{4}$
}

Received: 5 November 2021 / Revised: 15 November 2021 / Accepted: 17 November 2021 / Published online: 13 January 2022

(c) The Author(s), under exclusive licence to The Japanese Society of Hypertension 2022

\section{Dear Editor,}

We would like to thank you for the opportunity to respond to the issues raised in the letter related to our report and for providing detailed information to address these concerns. In the letter, the author noted concerns regarding a lower negative likelihood test not being employed during our evaluation of hyperaldosteronism screening [1]. We agree that, in general, a lower negative likelihood test can be effectively employed to avoid missing the detection of a disease.

In our study results, the possibility of hyperaldosteronism was low if the second morning urine $\mathrm{Na} / \mathrm{K}$ ratio ( $\mathrm{SMU} \mathrm{Na/K}$ ) was higher than 3.0 [2]. However, it is also important to use a screening tool to detect subjects for whom detailed examinations are appropriate. The probability of hyperaldosteronism is only $14.7 \%$, even if a subject's SMU Na/K is less than 3.0 (Table 3 in [2]. A larger number of people may reach a cutoff point set at 3.0 without either a special diet or strict dietary control since the mean urinary $\mathrm{Na} / \mathrm{K}$ ratio of people under the self-monitoring intervention reached 3.2 [3]. Thus, setting the cutoff point at 3.0 may lead to many unnecessary detailed examinations. It is reasonable to infer that patients showing a low urinary $\mathrm{Na} / \mathrm{K}$ should be identified

Akane Higashi

higashi-akane@kpu.ac.jp

1 Graduate School of Life and Environmental Sciences, Kyoto Prefectural University, Kyoto, Japan

2 Center for Epidemiologic Research in Asia, Shiga University of Medical Science, Shiga, Japan

3 Department of Mathematics and Statistics in Medical Sciences, Kyoto Prefectural University of Medicine, Kyoto, Japan

4 Department of Public Health, Shiga University of Medical Science, Shiga, Japan for additional screening for hyperaldosteronism. Therefore, we only mentioned hypertensive men with an extremely low SMU Na/K (e.g., $<1.0 \mathrm{mmol} / \mathrm{mmol}$ ) who would have a high possibility of hyperaldosteronism. We cannot employ a cutoff point in which the sensitivity and specificity are both high enough because our preliminary evaluation used the single spot urine $\mathrm{Na} / \mathrm{K}$ ratio, which is poor in reliability. Further investigations are needed for improved methods (e.g., multiple measurements of the spot urine $\mathrm{Na} / \mathrm{K}$ ratio, obtaining information related to patients' dietary habits) to determine more feasible methodologies in the future.

\section{Compliance with ethical standard}

Conflict of interest The authors declare no competing interests.

Publisher's note Springer Nature remains neutral with regard to jurisdictional claims in published maps and institutional affiliations.

\section{References}

1. Shimosawa T. Letter to the Editor regarding: Urinary sodium/ potassium ratio as a screening tool for hyperaldosteronism in men with hypertension. Hypertens Res. 2021. https://doi.org/10.1038/ s41440-021-00787-y.

2. Segawa H, Higashi A, Masuda I, Yoshii K, Iwahori T, Ueshima H. Urinary sodium/potassium ratio as a screening tool for hyperaldosteronism in men with hypertension. Hypertens Res. 2021;44:1129-37.

3. Iwahori T, Ueshima H, Ohgami N, Yamashita H, Miyagawa N, Kondo $\mathrm{K}$, et al. Effectiveness of a self-monitoring device for urinary sodium-to-potassium ratio on dietary improvement in freeliving adults: a randomized controlled trial. J Epidemiol. 2018;28:41-7. 